\title{
HOW TO GIVE A GREAT TALK
}

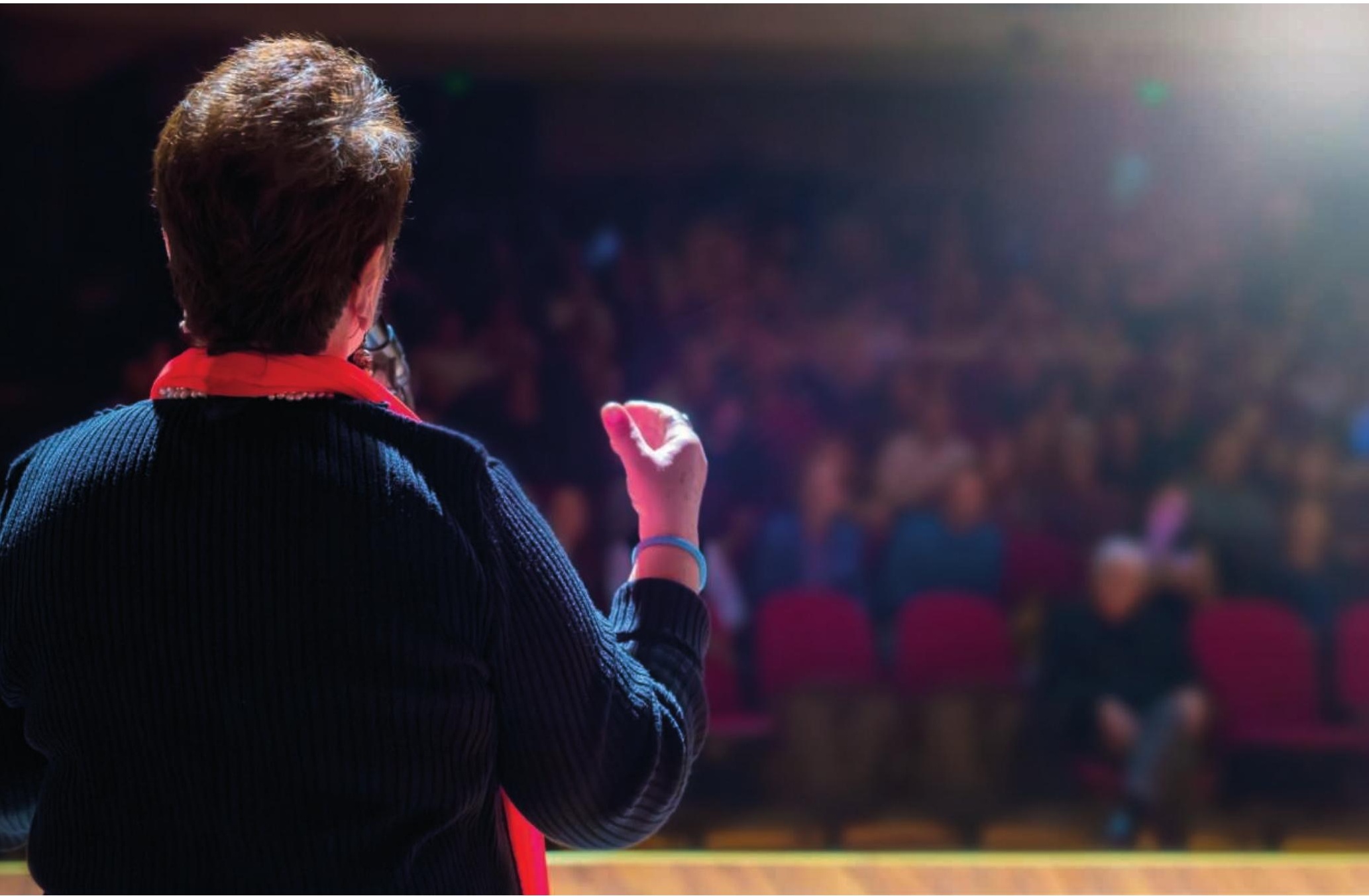

Expert presenters share advice on how to capture and hold the attention of a conference crowd.

\section{BY NIC FLEMING}

CC T t was horrific," says Eileen Courtney. "I was just a bundle of nerves. I wasn't able to eat for the whole of the previous day. That's when I realized I needed to get over my fear of public speaking."

Courtney is a third year $\mathrm{PhD}$ candidate studying interactions between metals and two-dimensional semiconducting materials at the University of Limerick, in the Republic of Ireland. Her moment of revelation came as she contemplated presenting her research at the Microscience Microscopy Congress in Manchester, United Kingdom, in July 2017.

The gut-punch feeling of dread that the prospect of being on stage can trigger will be familiar to many early-career scientists. It could be induced by an invitation to an international conference, an academic group meeting or a public engagement event. Or it might be caused by an all-important presentation as part of an interview process.

\section{"YOU HAVE TO THINK ABOUT THE LEAST KNOWLEDGEABLE PERSON IN YOUR AUDIENCE."}

Although the audiences and goals of a talk may differ, the skills and techniques required to pull it off are similar. So what differentiates a good presentation from a bad one? How can you up your game in front of the lectern? And is being able to impress an audience really all that important?

The answer to that last question is an emphatic yes, says Susan McConnell, a neurobiologist at Stanford University, in California, who has been giving talks on giving talks for more than a decade. "The whole point of doing science is to be able to communicate it to others," says McConnell. "Whether it is to our close colleagues, other scientists with a general interest in our area or to non-scientists, clarity of communication is essential."

Not all researchers recognize the value of taking time out of the lab to tell colleagues about their work. "Some have this idea that 


\section{ENGAGE LIKE A CHAMP}

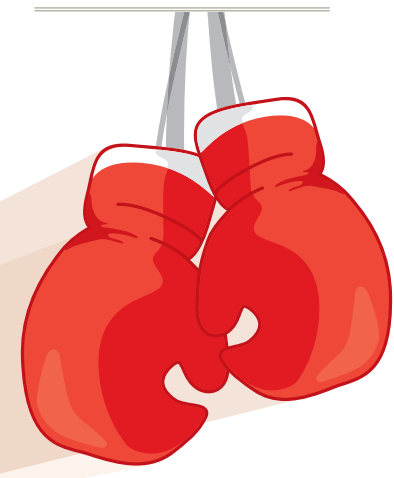

Great public speaking skills are not sufficient for good presenting, but they help. In August, Ramona J. Smith, a high-school teacher from Houston, Texas, was crowned Toastmasters 2018 World Champion of Public Speaking.

These are her top 10 tips, which she plans to outline in more detail in a forthcoming e-book.

01 Be yourself - people relate to and connect with authenticity.

01 Prepare, practice and perfect get rid of those crutch words, like 'um' and 'you know'.

Describe what you're telling us 3 use vivid words to help the audience paint a picture.

Vocal variety - change up your 04 tone, volume and pitch to keep the audience engaged.

05 Study the greats - watch what really great speakers do.

Get feedback - a practice audience can help you get the bugs out.

07 Appearance - if you look good, you'll feel good, which will help you give a great speech.

Pauses - they give the audience time to think, and help them engage.

Body language - use gestures and make use of the space to help deliver your message.

Be confident - use your face, body language and stance to own the stage. if you're spending time giving a talk, you're spending time on marketing which could be better spent doing science," says Dave Rubenson, co-founder of Los Angeles-based nobadslides.com, a company that provides courses on giving effective slide presentations. "In fact the process of creating a compelling talk and getting your audience to understand it improves both your understanding and theirs, and is central to science itself." On top of this, Rubenson says, presenting at conferences is a great way to attract the collaborators who can help you break new ground and advance in your career, but only if those listening understand what they're being shown.

A good place to begin is in your audience's shoes. They need to know early on why they should care about what you're saying. What is the 'story' at the heart of your presentation? Creating a concise summary of your talk, upon which you can add complexity, is a better starting point than pondering which of your file of 500 slides you can leave out, Rubenson says.

Presenters often fail because they try to deliver too much complex information. Language and content, normally, has to be designed with the non-specialist scientist in mind. "You have to think about the least knowledgeable person in your audience that you care about reaching," says Rubenson.

Another common mistake is the use of slides as 'data dumps'. Remember those times you've squinted at overly-busy slides packed with eight small graphs and wondered why the presenter mentions only one? Keep that in mind when designing your own slides. Animation software that lets you add information to slides as you talk about it can help.

Above all, it is important to maintain the focus of your audience.

You can help to prevent wandering minds by including summary slides at the end of sections. "You can think of a talk as a series of data dives," says McConnell. "You need to come up for air periodically, and say 'this is what we just learnt, this is the conclusion and this is how it links to the next part."

McConnell describes this and many more ways for researchers to improve their scientific presentation skills in a popular 42-minute online video. Another source of advice is the 2013 book Designing Science Presentations by American neuroscientist Matt Carter. While these offer useful pointers, most people find that when it comes to public speaking and presenting, practice makes, if not perfect, then certainly better.

That notion is central to Toastmasters International, a non-profit organization that helps individuals improve their public speaking skills through its network of more than 16,000 branches in 143 countries. At weekly or fortnightly meetings, members practice speeches and give each other feedback. It was to her local branch that Eileen Courtney turned last summer after

\section{CONQUER NERVES}

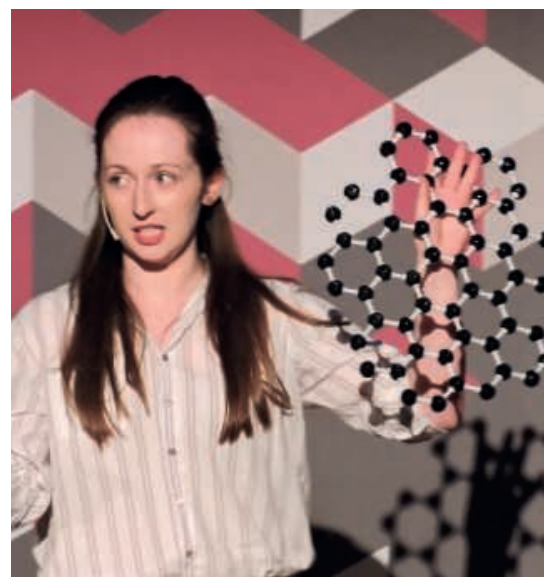

Different methods work for different people. Here are Eileen Courtney's tips for keeping calm at the lectern.

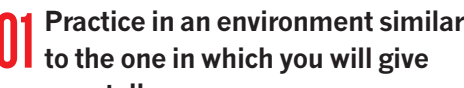
your talk.

02 Memorize key sentences within

02 an outline, rather than learning it word for word.

Ensure you are within the time

limit, so the clock is one less thing to worry about.

04

Wear something professional-looking and comfortable, not a new outfit.

Avoid overeating and limit coffee intake on the day itself.

realizing her presenting skills needed work. It seems her decision paid off. In May she was runner-up and audience favourite in the 3 Minute Wonder competition, a science communication challenge run by the Londonbased Institute of Physics in which entrants have one slide and 180 seconds to present their research to non-specialists.

"I've recently had to give other presentations and I've calmed down a lot, as a result of both going to Toastmasters and through teaching as part of my PhD," says Courtney. "As you get more experience of speaking in front of a crowd, it becomes a lot less scary." -

Nic Fleming is a freelance science writer based in Bristol, United Kingdom. 